\title{
Perianal Actinomycosis: A Surgeon's Perspective and Review of Literature
}

\author{
Alexios Dosis ${ }^{1}$, Atia Khan ${ }^{1}$, Henrietta Leslie ${ }^{1}$, Sahar Musaad $^{2}$, Adrian Smith ${ }^{1}$ \\ ${ }^{1}$ Department of General Surgical, Calderdale and Huddersfield NHS Foundation Trust, Huddersfield; ${ }^{2}$ Department of Microbiology, \\ Calderdale and Huddersfield NHS Foundation Trust, Huddersfield, United Kingdom
}

Actinomycosis is a serious suppurative, bacterial infection caused by the gram-positive anaerobic Actinomyces species. Primary perianal actinomycosis is rare and challenging for the colorectal surgeon. We aimed to present our experience and compare this with available literature. All patients with isolated Actinomyces on microbiology reports, between January 2013 and February 2021, were identified and reviewed. Data collection was retrospective based on electronic patient records. The site of infection and treatment strategy were examined. Perianal cases were evaluated in depth. All publications available in the literature were interrogated. Fifty-nine cases of positive actinomycosis cultures were reviewed. Six cases of colonization were excluded. Actinomyces turicensis was the most common organism isolated. Five cases of perianal actinomycosis were identified requiring prolonged antibiotic and surgical therapy. Twenty-one studies, most case reports, published since 1951 were also reviewed. Diagnosis of perianal actinomycosis may be challenging but should be suspected particularly in recurrent cases. Prolonged bacterial cultures in anaerobic conditions are necessary to identify the bacterium. An extended course of antibiotic therapy (months) is required for eradication in certain cases.

\section{Keywords: Actinomycosis; Abscess; Anal canal; Fistula}

\section{INTRODUCTION}

Perianal sepsis is a common problem for the general surgeon, presenting either as an acute abscess or anal fistula. In the United Kingdom, the annual incidence is estimated between 21.5 and 30.8 per 100,000 population [1]. Etiology, however, has not been fully proven. Chiari was the first to describe in 1878 the anal glands that discharge at the mucocutaneous junction of the anal canal into the anal crypts [2]. The pathogenesis of perianal suppu-

Received: May 11, 2021 - Revised: Sep 26, 2021 - Accepted: Sep 29, 2021 Correspondence to: Alexios Dosis, M.D., MRCS.Ed., M.Sc.

Department of General Surgery, Calderdale and Huddersfield NHS

Foundation Trust, Acre St., Lindley, Huddersfield HD3 3EA, UK

Tel: +44-7754226212, Fax: +44-1484342888

E-mail: alexisdosis@icloud.com, Alexios.Dosis@doctors.org.uk ORCID: https://orcid.org/0000-0003-1415-6156

- The audit part of the paper has been presented as a poster at the annual meeting of the Association of Surgeons of Great Britain and Ireland (ASGBI 2019) on May 8, 2019, in Telford, United Kingdom.

(C) 2021 The Korean Society of Coloproctology

This is an open-access article distributed under the terms of the Creative Commons Attribution NonCommercial License (https://creativecommons.org/licenses/by-nc/4.0) which permits unrestricted noncommercial use, distribution, and reproduction in any medium, provided the original work is properly cited. ration is currently attributed to those anal crypts getting blocked by debris or stool, which subsequently results in cryptitis and formation of abscess [3]. The majority of cases can be usually dealt with without complications, yet a small number can pose a significant challenge for both patient and surgeon. These cases are often associated with a variety of conditions such as Crohn's disease, lymphogranuloma venereum, tuberculosis, or actinomycosis.

Actinomycosis involving the perianal region can be quite complex with recurrent abscesses, multiple draining sinuses, and fistulas in ano. This form of the disease is a rare entity and not generally appreciated. Proper treatment is often delayed for months or even years as early detection requires a high index of suspicion [4]. The aim of this study was to review and present our experience in a district general hospital and raise awareness of this rare form of the disease.

\section{METHODS}

Our institution consists of 2 major hospitals that serve an area of more than 500,000 residents. All bacteriology reports related to Actinomyces species, between January 2013 and February 2021, were identified from a prospectively maintained electronic data- 
base. Only positive cultures for Actinomyces species were included in the study. Histology reports were also examined to confirm diagnosis wherever possible. Retrospective clinical data were additionally obtained from institutional electronic patient records by 3 separate clinicians. Site of infection, treatment strategy, and baseline characteristics of patients were collected. All cases of perianal disease were identified and a more detailed review of these was undertaken. No ethical approval was required for this study as it was performed as part of a local audit process. In order to publish relevant imaging, written informed consent was subsequently obtained from 2 patients.

A comprehensive literature search was also performed parallel to the study to identify publications relevant to perianal actinomycosis. The following keywords and Medical Subject Heading $(\mathrm{MeSH})$ terms were used: "actino,", "anorectal," "anorectum," and "perianal." The online bibliographic databases of PubMed, Medline, and Embase were searched for all citations published in English between May 1950 and April 2021. Selection was limited to human studies only. Initially, titles and abstracts were screened to identify papers reporting actinomycosis of the perianal region. Subsequently, a full-text review of the remaining studies was performed.

\section{RESULTS}

One hundred and eighty bacteriology reports of Actinomyces species were scrutinized and 59 cases were identified with positive

Table 1. Overview of positive cultures for Actinomyces over 8 years

\begin{tabular}{lcccc}
\hline Site & $\begin{array}{c}\text { Positive } \\
\text { culture }\end{array}$ & $\begin{array}{c}\text { Prolonged } \\
\mathrm{ABx}\end{array}$ & Recurrence & $\begin{array}{c}\text { Further } \\
\text { surgery }\end{array}$ \\
\hline Perianal & 5 & $3(60.0)$ & 3 & 3 \\
Pilonidal & 15 & $3(20.0)$ & 4 & 4 \\
Cutaneous & 21 & $5(23.8)$ & 7 & 4 \\
Others $^{\text {a }}$ & 12 & $4(33.3)$ & 1 & NA \\
\hline
\end{tabular}

Values are presented as number only or number (\%).

$\mathrm{ABx}$, antibiotic therapy; NA, not available.

aOthers included abdominal, cervicofacial; and 2 patients suffered from systemic disease.
Actinomyces culture. Six of these cases represented colonization and were therefore excluded from the analysis. The median age of included patients was 33 years and male to female ratio was 1:3. Mixed growth of Actinomyces species was observed in 39.6\% of the cases (21 of 53), but the most commonly isolated subtype was Actinomyces turicensis in 34.0\% (18 cases). Other less common subtypes included Actinomyces neuii, Actinomyces meyeri, and Actinomyces israeli with 5, 3, and 2 cases, respectively.

Positive cultures for Actinomyces were identified predominantly in patients with soft tissue infections (breast, back and groin abscesses, or dehisced infected wounds). Natal cleft comprised the second commonest site, whereas only 5 cases involving the anorectum were detected (Table 1). Other areas where Actinomyces were isolated included cervicofacial and abdominal regions. There were 2 cases of systemic actinomycosis isolated in blood cultures. One death was recorded in the series and this was related to systemic actinomycosis with rapid hematogenous spread and formation of multiple brain abscesses.

In the perianal cohort (Table 2), 3 of the 5 patients with positive cultures suffered recurrent episodes of infection resulting in complex disease with chronic and multiple anal fistulas and sinus tracts requiring further surgery and prolonged treatment with antibiotics. Histological evidence of sulfur granules was detected in only 1 patient that validated the diagnosis.

The operation usually involved drainage of sepsis as a first step. None of the patients had macroscopic evidence of sulfur granules on the initial procedure. For those with a recurrence, a number of return journeys to theatre were required (range, 3-6). This usually comprised examination under anesthesia of the anorectum with either drainage of sepsis, seton insertions, and/or fistulectomy depending on the occasion and surgeon's decision. Magnetic resonance imaging (MRI) with contrast of the pelvis was used in all 3 patients with the recurrence to guide surgical management. According to Parks classification of fistulae [2], patient 2 had multiple transsphincteric fistulae and 1 supralevator with 2 external openings, patient 3 had 4 transsphincteric and 1 intersphincteric fistula, and patient 5 had multiple sinus tracts extending to the perineum but no formal fistula was identified on MRI scan or surgery. Fig. 1 shows images of the 65 -year-old male with

Table 2. Review of the 5 patients with perianal disease

\begin{tabular}{|c|c|c|c|c|c|c|c|c|}
\hline $\begin{array}{l}\text { Patient } \\
\text { No. }\end{array}$ & $\begin{array}{l}\text { Age } \\
\text { (yr) }\end{array}$ & Sex & Comorbidity & Diagnosis & Species & Recurrence & Antibiotic therapy & $\begin{array}{c}\text { Duration } \\
\text { (week) }\end{array}$ \\
\hline 1 & 42 & Female & Diabetes, Graves disease & Cultures & Actinomyces israeli & No & $\begin{array}{l}\text { Metronidazole+amoxicillin+ } \\
\text { clavulanic acid }\end{array}$ & 2 \\
\hline 2 & 26 & Female & Fit & Cultures+histology & Actinomyces turicensis & Yes & Ceftriaxone+metronidazole & 30 \\
\hline 3 & 65 & Male & IHD, COPD, CKD & Cultures & Actinomyces meyeri & Yes & Amoxicillin+clarythomycin & NR \\
\hline 4 & 36 & Male & Behçet disease & Cultures & Actinomyces turicensis & No & Amoxicillin & 2 \\
\hline 5 & 49 & Male & None reported & Cultures & Mixed & Yes & Amoxicillin & 6 \\
\hline
\end{tabular}

IHD, ischemic heart disease; COPD, chronic obstructive pulmonary disease; CKD, chronic kidney disease; NR, not reported. 


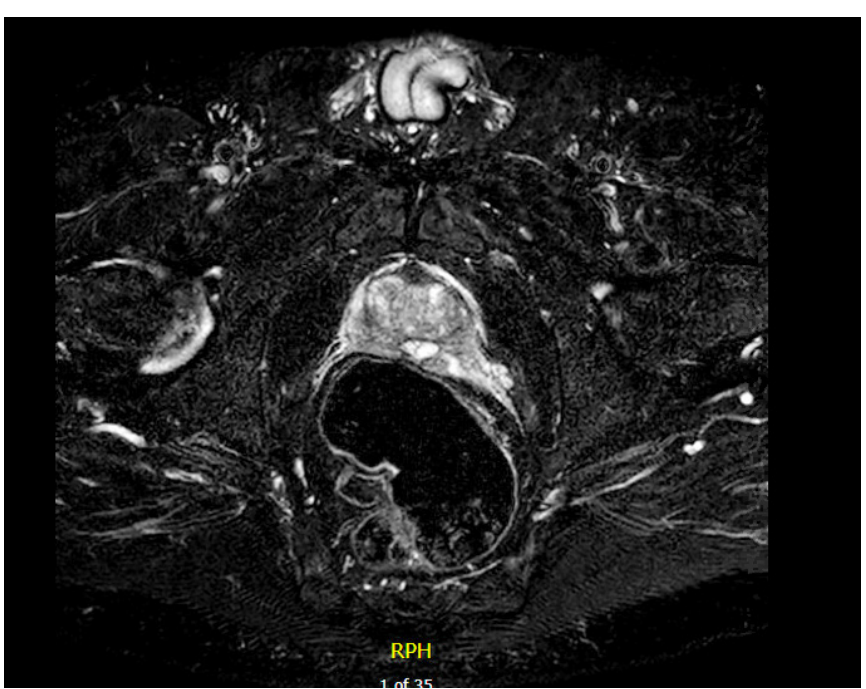

Fig. 1. Magnetic resonance imaging of pelvis STIR sequence with contrast of the 65-year-old male with perianal actinomycosis. At 12:00, there is an intersphincteric and extrasphincteric $8 \mathrm{~mm}$ fluid collection which continues with a small tract to the right side of the buttock up to the subcutaneous surface around 8 o'clock.

deep intersphincteric and extrasphincteric fluid collections.

Antibiotic choice varied between cases but usually a combination of either amoxicillin or cephalosporin and metronidazole was necessary. As no clear guidelines were available, antibiotic choice was planned in conjunction with the microbiologist. Initial length of treatment was decided for 6 weeks depending on response. However, the 26-year-old female patient suffered a recurrence while on antibiotics and therefore a course of 30 weeks in total was essential. In 1 of the male patients, the 49-year-old, the disease spread superiorly into the perineum and scrotal involvement was also observed (Fig. 2). All patients with recurrence were followed up in an outpatient setting to confirm resolution of the disease.

As shown in Table 1, prolonged antibiotic therapy combined with further surgery was also observed in patients with soft tissue (23.8\%) and pilonidal infection (20.0\%) for recurrence.

All publications related to perianal actinomycosis since 1951 are listed in Table 3 [4-24]. As anorectal involvement is a rare manifestation of the disease most of the studies included here are actually case reports or case series. No randomized trials or prospective studies were identified. Mean duration of antibiotic therapy was prolonged and varied from weeks to even years $[16,23]$. The weighted average was 8.3 weeks across studies with available date. The largest cohort comes from Brewer et al. [4] with 9 patients over a 22 -year period.

\section{DISCUSSION}

Actinomycosis is a rare but potentially serious bacterial infection

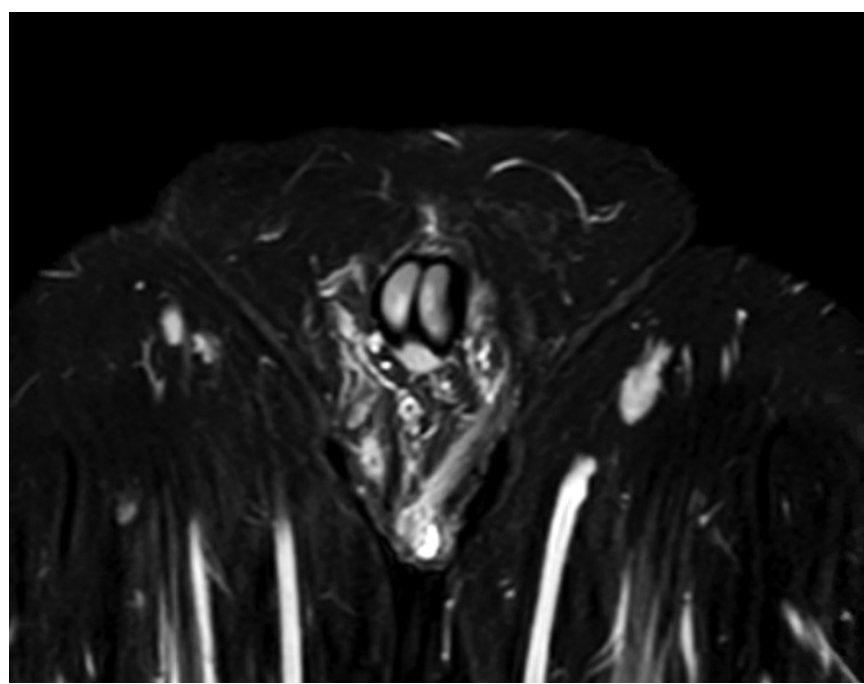

Fig. 2. Magnetic resonance imaging of pelvis STIR sequence with contrast of the 49 -year-old male. There is a small collection with a thick enhancing wall at the base of the left scrotum extending posteriorly to the left perineum. The collection measures $2.0 \times 0.7 \times 2.1$ $\mathrm{cm}$. No fistula or communication with the anus.

caused by the gram-positive anaerobic filamentous bacilli of the Actinomyces species. The bacteria belong to the genus of the Actinobacteria group and they are predominantly anaerobic commensals of the oropharynx, urogenital, and gastrointestinal tract [25]. The exact mechanism that leads to overt disease is still unknown, as actinomycosis occurs in both immune-competent and immune-compromised patients [5]. Sanford and Voelker published the first large series of the disease in 1925, reporting 670 cases of actinomycosis of various anatomical sites. Interestingly they described only 5 cases related to the perianal region [21]. The infection commonly occurs in the cervicofacial, thoracic, and abdominopelvic regions [25]. Anorectal involvement may result from a secondary extension of an abdominal infection or may arise primarily in the anorectal region [4]. Primary perianal actinomycosis is generally quite rare with only a few reports published in the literature. Egal et al. [5] found the condition to represent less than $0.2 \%$ of all fistulae in ano in their series.

The anorectal form usually begins in an anal crypt where it evolves as a chronic bacterial infection that is characterized by slowly progressing suppurative fibrosing inflammation, development of draining sinus tracts that may discharge characteristic "sulfur granules" and direct dissemination via adjacent tissues [21, 26]. The acute phase is rarely recognized due to the insidious onset, and the diagnosis is nearly always late [21]. It can often be misdiagnosed because it mimics other more common conditions such as malignancy and tuberculosis [27].

Diagnosing actinomycosis is challenging. Patients may give a protracted history of operations involving repeated attempts for drainage of perianal abscess, or fistulotomies [4]. There is a wide 
Table 3. Publications reporting perianal actinomycosis since 1951 listed here in reverse chronological order

\begin{tabular}{|c|c|c|c|c|}
\hline Study & Year & No. of patients & Diagnosis & $A B x$ duration $(w k)^{a}$ \\
\hline Egal et al. [5] & 2018 & 7 (new) & Cultures and histology & 36 \\
\hline Ferreira Cardoso et al. [6] & 2017 & 1 & Cytology & 24 \\
\hline Ablett et al. [8] & 2012 & 1 & Histology & 24 \\
\hline Magdeburg et al. [9] & 2008 & 1 & Cultures & 12 \\
\hline Bauer et al. [11] & 2006 & 6 & Cultures and histology & $21(4-78)$ \\
\hline Coremans et al. [12] & 2005 & 3 & Cultures (3) and histology (2) & $6(2-16)$ \\
\hline Leung et al. [13] & 2004 & 1 & Histology & NR \\
\hline Gayraud et al. [14] & 2000 & 2 & Cultures & NR \\
\hline Posnik et al. [15] & 1996 & 1 & Histology & NR \\
\hline Harris and Metcalf [19] & 1988 & 1 & Cultures & 8 \\
\hline Shimada et al. [20] & 1986 & 1 & Cultures & 8 \\
\hline Brewer et al. [4] & 1974 & 9 & Cultures (8) and histology (1) & $16(4-64)$ \\
\hline Samenius [21] & 1970 & 5 & Histology & $>2$ \\
\hline Punyamurthy and Shenoi [22] & 1968 & 1 & Histology & NR \\
\hline Anscombe and Hofmeyr [23] & 1954 & 1 & Histology and cultures & 36 \\
\hline Gordon and DuBose [24] & 1951 & 1 & Histology and cultures & NR \\
\hline
\end{tabular}

ABx, antibiotic therapy; NR, not reported.

aMean (range).

range of differentials such as inflammatory bowel disease, tuberculosis, malignancy, hidradenitis suppurativa, lymphogranuloma venereum, and syphilis [12]. Patients usually undergo a variety of tests including endoscopic procedures with biopsies, computed tomography, and virology tests.

Isolation and identification of the causative bacteria occur in only a minority of cases. Demonstration of Gram-positive filamentous organisms and sulfur granules on histological examination is strongly supportive of the diagnosis of actinomycosis. Direct isolation of the organism from a clinical specimen or from sulfur granules is usually required for a definitive diagnosis. However, the failure rate of isolation is particularly high (>50\%) for various reasons. These include previous antibiotic treatment, overgrowth of concomitant organisms, or occasionally inadequate methodology [27]. Gram staining of pus and pathology of infected tissue is of great value, as it is often more sensitive compared to plain culture which remains sterile in more than $50 \%$ of cases [25]. Common practice is to send only bacterial swabs from the perianal abscess, but rarely the tissue. Several series such as Egal et al. [5] have been published with good evidence that sending both specimens to the laboratory at every surgery is important.
Histological analysis of all excised tissue from fistulas and abscesses should be carried out routinely. Clinicians should alert the laboratory to expect the specimen and specifically request for actinomycosis to ensure that prolonged culture on appropriate media is performed; Actinomyces are slow-growing organisms that need to be cultured anaerobically for up to 3 weeks [27]. Molecular methods, such as polymerase chain reaction and $16 \mathrm{~s}$ ribosomal RNA sequencing have been proven to be powerful tests in confirming and/or identifying Actinomyces species [28].

In our series, contradicting standard practice, all cases were identified from positive cultures, and in only 1 occasion diagnosis was confirmed histologically with positive gram stain. It is likely that some cases especially soft tissue infections, may not represent a typical actinomycetic lesion [28] but simple infections involving Actinomyces species. For the perianal group that we particularly focused on, we believe that only 3 out of 5 cases represent true actinomycosis and those are the patients with recurrent episodes requiring prolonged antibiotic treatment. Interestingly macroscopic evidence of sulfur granules was not identified in any of them. From our experience, culture of the affected tissue is of great significance, particularly in cases of diagnostic dilemma. 
Currently, there are no standardized guidelines on antibiotic therapy. Our choice was usually amoxicillin with a combination of anaerobic cover (metronidazole or clavulanic acid). In vitro studies have reported that Actinomyces are susceptible to a wide range of antimicrobial agents. A UK study of 87 clinical isolates of Actinomyces showed that most were susceptible to $\beta$ lactams (including benzylpenicillin, amoxicillin, ceftriaxone, meropenem, and piperacillin-tazobactam), doxycycline, clindamycin, erythromycin, and clarithromycin. Species identification was found to be crucial because of resistance to some antibiotics [29]. Although several antibiotic regimens may be used, the most preferable first choice remains intravenous penicillin, specifically 10-20 million units per day of penicillin G over 2 to 6 weeks, divided 4 times a day, followed by therapy with penicillin $\mathrm{V}$ or amoxicillin for 6 to 12 months [11]. Certain antibiotics are, nonetheless, considered to be ineffective, including quinolones, aminoglycosides, and first-generation cephalosporins [30]. Appropriate duration is a matter of debate although in most series patients received antibiotics for a minimum of 6 months. Regular long-term follow-up of the patient is paramount during extended antibiotic treatment to ascertain adherence and to assess for clearance of the infection. The mean duration of follow-up in the colorectal clinic in our series was 18 months.

\section{CONCLUSION}

Perianal actinomycosis is a rare form of the disease and has only been described in isolated case reports and small series. Surgeons should be aware of the possibility of actinomycosis as the cause of indolent perianal abscesses. Diagnosis is challenging requiring a high level of clinical suspicion. Prolonged bacterial cultures are necessary to identify the bacterium. Adequate surgical drainage and exploration of sinus tracts appear beneficial but not always adequate. Treatment strategy and decisions should be on a caseby-case basis as an extended course of antibiotic therapy may be required for eradication. Surgical drainage and exploration of sinus tracts appear beneficial but not always sufficient.

\section{CONFLICT OF INTEREST}

No potential conflict of interest relevant to this article was reported.

\section{ACKNOWLEDGMENTS}

The author would like to thank the Drs. Atia Khan and Henrietta Leslie for their valuable contribution in data collection as well as Dr. Sahar Musaad for her support and advice.

\section{REFERENCES}

1. Sahnan K, Adegbola SO, Tozer PJ, Watfah J, Phillips RK. Perianal abscess. BMJ 2017;356:j475.

2. Parks AG, Gordon PH, Hardcastle JD. A classification of fistulain-ano. Br J Surg 1976;63:1-12.

3. Ross ST. Fistula in ano. Surg Clin North Am 1988;68:1417-26.

4. Brewer NS, Spencer RJ, Nichols DR. Primary anorectal actinomycosis. JAMA 1974;228:1397-400.

5. Egal A, Etienney I, Beate H, Fléjou JF, Cuenod CA, Atienza P, et al. Diagnosis and management of a cryptoglandular actinomycotic fistula-in-ano: an update on 7 new cases and a review of the literature. Ann Coloproctol 2018;34:152-6.

6. Ferreira Cardoso M, Carneiro C, Carvalho Lourenço L, Graça Rodrigues C, Folgado Alberto S, Alagoa João A, et al. Actinomycosis causing recurrent perianal fistulae. ACG Case Rep J 2017;4: e82.

7. Dumitru E, Dumitru IM, Popescu R, Resul G, Bulbuc I, Rugina S. Simultaneous occurrence of two rare diseases: actinomycosis and melanoma of the rectum. J Gastrointestin Liver Dis 2014;23:95-8.

8. Ablett DJ, Wylie JR, Berlansky MS. Perianal actinomycosis: a case study of this rare infection associated with nicorandil usage. Scott Med J 2012;57:60.

9. Magdeburg R, Grobholz R, Dornschneider G, Post S, Bussen D. Perianal abscess caused by Actinomyces: report of a case. Tech Coloproctol 2008;12:347-9.

10. Gupta PJ. Perianal actinomycosis mimicking as multiple fistulae in ano. N Z Med J 2008;121:99-101.

11. Bauer P, Sultan S, Atienza P. Perianal actinomycosis: diagnostic and management considerations: a review of six cases. Gastroenterol Clin Biol 2006;30:29-32.

12. Coremans G, Margaritis V, Van Poppel HP, Christiaens MR, Gruwez J, Geboes K, et al. Actinomycosis, a rare and unsuspected cause of anal fistulous abscess: report of three cases and review of the literature. Dis Colon Rectum 2005;48:575-81.

13. Leung TK, Lee CM, Hsu CH, Chen HC. MRI findings of perianal abscess due to actinomycosis. Chin J Radiol 2004;29:153-6.

14. Gayraud A, Grosieux-Dauger C, Durlach A, Salmon-Ehr V, Elia A, Grosshans E, et al. Cutaneous actinomycosis in the perianal area and buttocks. Ann Dermatol Venereol 2000;127:393-6.

15. Posnik MR, Potesman I, Abrahamson J. Primary perianal actinomycosis. Eur J Surg 1996;162:153-4.

16. Alvarado-Cerna R, Bracho-Riquelme R. Perianal actinomycosis: a complication of a fistula-in-ano: report of a case. Dis Colon Rectum 1994;37:378-80.

17. Fry RD, Birnbaum EH, Lacey DL. Actinomyces as a cause of recurrent perianal fistula in the immunocompromised patient. Surgery 1992;111:591-4.

18. Mast P, Vereecken L, Van Loon C, Hermans M. Actinomycosis of the ano-rectum: a rare infectious disease mimicking carcinomatosis. Acta Chir Belg 1991;91:150-4.

19. Harris GJ, Metcalf AM. Primary perianal actinomycosis. Report of a case and review of the literature. Dis Colon Rectum 1988;31: 311-2.

20. Shimada M, Kotani T, Ohtaki S, Tateno S, Tanigawa H, Katsuki T. 


\section{Coloproctology

Primary perianal actinomycosis over a thirty year period. Jpn J Surg 1986;16:302-4.

21. Samenius B. Actinomycosis of the anorectal region. Proc R Soc Med 1970;63(Suppl 1):108-11.

22. Punyamurthy M, Shenoi BV. Multiple perianal fistulae due to actinomycosis. J Indian Med Assoc 1968;51:396-7.

23. Anscombe AR, Hofmeyr J. Perianal actinomycosis complicating pilonidal sinus. Br J Surg 1954;41:666.

24. Gordon MA, DuBose HM. Anorectal actinomycosis with extensive gluteal and thigh involvement; report of a case. Am J Clin Pathol 1951;21:460-3.

25. Valour F, Sénéchal A, Dupieux C, Karsenty J, Lustig S, Breton P, et al. Actinomycosis: etiology, clinical features, diagnosis, treatment, and management. Infect Drug Resist 2014;7:183-97.

26. Fazili T. Actinomyces species (actinomycoses) [Internet]. E-Sun
Technologies; c2017 [cited 2019 Jan 2019]. Available from: http:// www.antimicrobe.org/b73.asp.

27. Wong VK, Turmezei TD, Weston VC. Actinomycosis. BMJ 2011; 343:d6099.

28. Hansen JM, Fjeldsøe-Nielsen H, Sulim S, Kemp M, Christensen JJ. Actinomyces species: a Danish survey on human infections and microbiological characteristics. Open Microbiol J 2009;3:11320.

29. Smith AJ, Hall V, Thakker B, Gemmell CG. Antimicrobial susceptibility testing of Actinomyces species with 12 antimicrobial agents. J Antimicrob Chemother 2005;56:407-9.

30. Marchand-Austin A, Rawte P, Toye B, Jamieson FB, Farrell DJ, Patel SN. Antimicrobial susceptibility of clinical isolates of anaerobic bacteria in Ontario, 2010-2011. Anaerobe 2014;28:120-5. 